\title{
Sexual function in spinal cord injury men. I. Assessing sexual capability
}

\author{
F J Courtois $\mathrm{PhD},{ }^{1} \mathrm{~K}$ F Charvier MD ${ }^{2}$ A Leriche MD ${ }^{2} \mathrm{D}$ P Raymond $\mathrm{MD}^{1}$ \\ ${ }^{1}$ Institut de réadaptation de Montréal, 6300 Darlington, Montréal, Quebec, H3S 2J4, \\ Canada; ${ }^{2}$ Hôpital Henry Gabrielle, 69230 Lyon, France.
}

\begin{abstract}
Precise diagnoses are seldom made upon complaints of sexual dysfunction by spinal cord injured men. The dysfunction is inevitably attributed to the neurological condition and available treatments are offered with little knowledge of the individual residual capacity or other contributing factors. Current practice emphasizes these treatment approaches, but the high rejection rate associated with the most widely used technique of intracavernous injections suggests that remaining sexual function should also be investigated. This study explores remaining function using physiological recording techniques and classifying the subjects according to the innervation of the reproductive system. The results show that, with objective measurements and proper classification of the subjects, $100 \%$ of individuals with high lesions maintain penile responses to reflexogenic stimulation and up to $90 \%$ of those with lower lesions maintain penile responses to psychogenic stimulation. These latter subjects also show naturally occurring emissions in $100 \%$ of the cases when they suffer from lesions to the conus terminalis and when they use psychogenic stimulation as a means of inducing erection and emission. Results from subjective reports reveal that spinal cord injured men underestimate their sexual capacity, while diagnoses based on clinical findings are better predictors.
\end{abstract}

Keywords: penile erection; sexual function; paraplegia; tetraplegia; spinal cord injuries.

\section{Introduction}

Assessment is a key element in clinical practice, as it provides the clinician with a diagnosis upon which treatment can be based. Physicians prescribe blood tests, urine tests, biopsies, xrays, EMGs and the like to document a patient's initial complaint. Psychologists develop intelligence tests, personality inventories, depression scales, and projective techniques to identify a client's disorder on a multiaxial classification system.

Despite this general use of assessment, clinical practice seldom proceeds to further diagnosis upon complaint of erectile dysfunction by spinal cord injured men. The dysfunction is generally attributed to the neurological condition and available treatments are offered with very little knowledge of the patient's residual capacity or other contributing factors.

Treatments that are offered include intracavernous injections, ${ }^{1-6}$ penile implants, ${ }^{7-11}$ external vacuum devices ${ }^{12-14}$ and applications of nitroglycerin. ${ }^{15-17}$ While these techniques cover a wide range of the patients' needs, complications as well as dissatisfaction occur in many instances. Studies on intracavernous injections, for example, show that up to $50 \%$ of the patients either refuse or are dissatisfied with the procedure. ${ }^{2}$ Studies on penile prosthesis similarly show complications ${ }^{18,19}$ and are now more often replaced by injection techniques.

While the search for refined techniques should definitely be emphasized, parallel studies on the remaining function of spinal cord injured men should not be underestimated. Early reports have shown that spinal cord injured men maintain a residual sexual function ${ }^{20-23}$ and it is surprising to note that very few studies have further explored this remaining capacity using physiological recording techniques. ${ }^{24,25}$

This paper describes a specific approach 
used to evaluate the sexual function of spinal cord injured men. A diagnosis and subsequent prognosis is made and compared to the subjects' physiological function. Subjective reports are also recorded and compared to physiological recordings.

\section{Materials and methods}

\section{Subjects}

The subjects were spinal cord injured men whose lesions were classified according to the dual innervation of the male reproductive system: the lesions were not classified using the natural divisions of the spinal cord but according to the sacral and thoraciclumbar innervation.

This classification system differs from most studies on sexual function in spinal cord injury ${ }^{20,22,23,26-28}$ which subdivide subjects into cervical, thoracic and lumbar groups. We believe that this natural division is not consistent with the innervation of the male reproductive system and is therefore misleading when it comes to estimating the remaining sexual function of paraplegic and tetraplegic men.

The dual innervation of the male genitals, along with the rationale used for subject classification, are illustrated in Figure 1. Diagram A shows that two pathways innervate the genitals: one originating from the sacral segments S2, S3, S4 and running to the penis via the pelvic nerves (for autonomic function) and the pudendal nerves (for somatic function); and one originating from the thoracic-lumbar (TL) segments T11-L2 and running to the penis via the hypogastric nerves, after relays in the coeliac and mesenteric ganglia. Under normal conditions, genital stimulation induces erection through a reflex arc and sends information to the brain to allow perception of erection. Psychogenic stimulation from the brain can also feed into the spinal pathways to trigger, enhance or inhibit erection. However, following a spinal cord injury, higher CNS structures may be completely or incompletely disconnected from spinal segments. Sexual responses may therefore be induced by genital or psychogenic stimulation, but not necessarily both, depending upon the extent of the neurological lesion.
Based on the distinction between stimulation sources and lesion levels, the subjects were classified according to the system illustrated in diagrams B, C, D and E of Figure 1. Considering complete lesions, where only optimal stimulation can be effective, diagram $B$ shows that subjects with lesions above the sacral and the thoracic-lumbar pathways should maintain sexual responses to local stimulation of the genitals, but not to psychogenic stimulation. It is noteworthy that subjects in this group can present heterogeneous lesions with respect to the natural divisions of the spinal cord and can include paraplegic men with thoracic lesions as well as tetraplegic men with cervical lesions. Those with partial lesions are similarly expected to have an erectile capacity to genital stimulation, but can also present additional responses to psychogenic stimulation.

Diagram $C$ shows that subjects with lesions between the two pathways are expected to maintain sexual responses to both genital and psychogenic stimulation, but to lose the additive effect of these two stimulation sources at the spinal level. This group is again composed of heterogeneous subjects with respect to the natural divisions of the spinal cord and can include individuals with lesions to the lower lumbar segments (L3, L4, L5) as well as the upper sacral segment.

Diagrams D and E show that subjects' lesions to the sacral pathway are further divided into lesions to the conus terminalis (diagram D) and lesions to the cauda equina (diagram $\mathrm{E}$ ). The rationale behind this subdivision is that damage to the conus terminalis may be restricted to the sacral segments and can therefore leave the TL pathway functional. Lesions to the cauda equina, in contrast, may involve damage to more than the immediate sacral fibres and may interfere with TL transmission. The first group may therefore present psychogenic erection more often than the second group. As with other lesions, partial damage is expected to allow responses to the alternate form of stimulation (i.e. reflexogenic) in addition to basic responses to the optimal mode of stimulation (i.e. psychogenic).

Originally, the four groups were sub- 


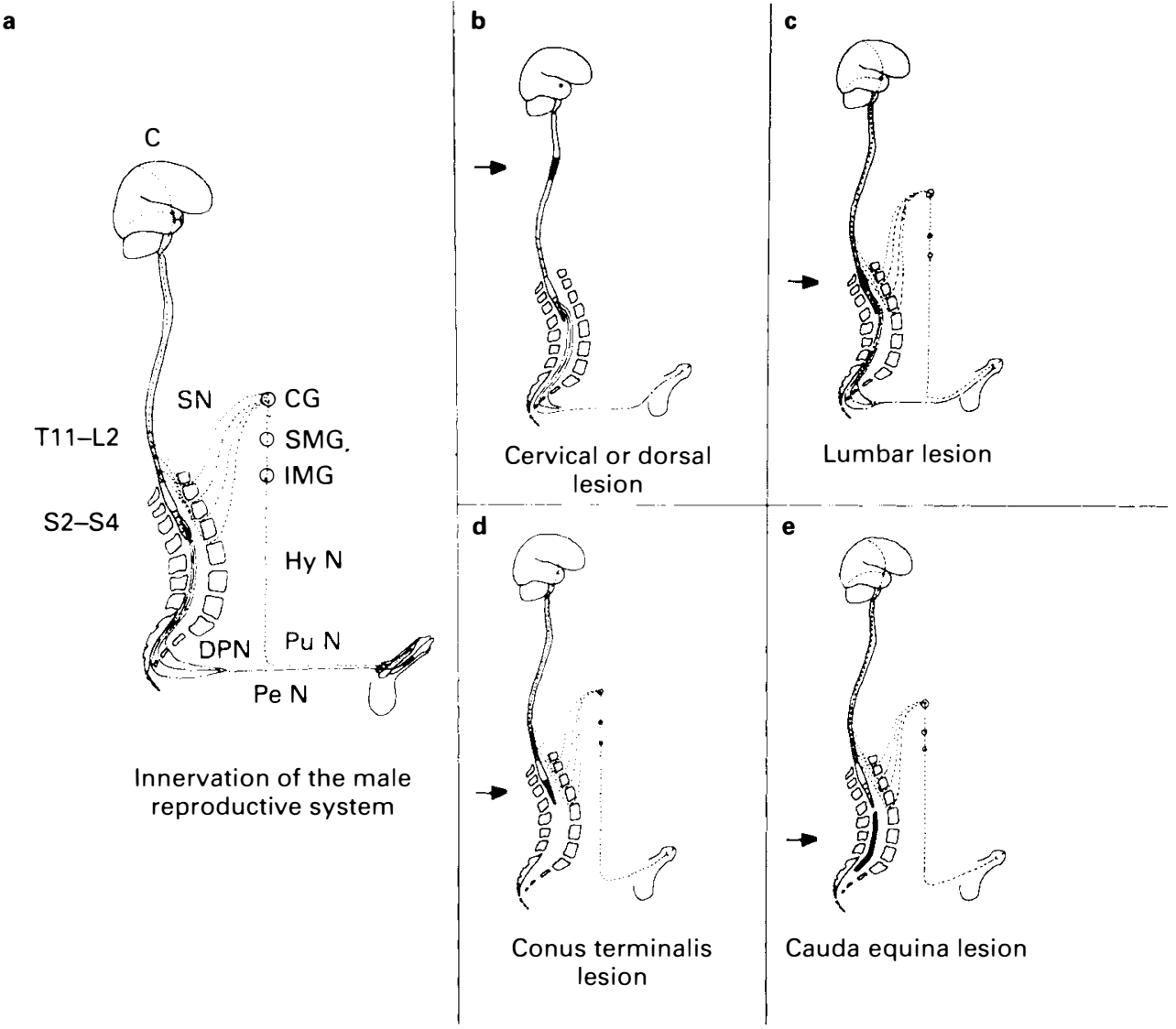

Figure 1 (a) Innervation of the male reproductive system with the sacral (S2-4) and thoraciclumbar (T11-L2) pathways. Abbreviations are as follows: C, cortex; CG, coeliac ganglion; DPN, dorsal penile nerve; IMG, inferior mesenteric ganglion; PeN, pelvic nerve; PuN, pudendal nerve; SMG, superior mesenteric ganglion; SN, splanchic nerve. (b) Lesion above the two pathways of erection, which maintains reflexogenic erection only. (c) Lesion between two pathways, which maintains both types of erection. (d) Lesion to the conus terminalis, which maintains psychogenic erection. (e) Lesion to the cauda equina, which maintains psychogenic erection.

divided into complete and partial lesions. However, our experience as well as that of others $^{29}$ reveals that, with a thorough neurological examination, very few subjects show complete lesions. Our subjects were therefore generally divided into single groups for which sexual function was defined according to the individual's characteristics (see below). Subjects with lesions above the two pathways included a sufficient number of complete and partial lesions to justify a subdivision.

A total of 71 subjects were therefore divided into a group of 15 subjects with complete lesions above the two pathways of erection (AC), a group of 15 subjects with partial lesions above the two pathways (AP), a group of 13 subjects with lesions between both pathways (BTW), a group of 10 subjects with lesions to the conus terminalis (CT), and a group of 18 subjects with lesions to the cauda equina (CE). Missing data occasionally changed the number of subjects per group, as will be noticed in the results section.

\section{Procedure}

\section{Clinical interview}

The subjects were interviewed in the rehab- 
ilitation center where they had received consultation for sexual dysfunction (Institut de réadaptation de Montréal in Canada or Hôpital Henry Gabrielle in France). Consultation and investigation of sexual function were offered to all patients who generally showed eagerness to participate. Questions about sexual function were asked and are summarized in Table $\mathrm{I}$. The questions explored the subject's awareness of erectile capacity such as the occurrence of erection following reflexogenic, or psychogenic, stimulation as well as that occurring spontaneously or outside the context of intercourse. Ejaculatory activity was also noted as spontaneous emission which was defined as the emission of a whitish, viscous substance which could be expulsed or dribble along the urethra. The initial interview was followed by a neurological examination and physiological recordings.

\section{Neurological examination}

The neurological examination was essential to classify the subject's lesion with respect to the dual innervation of the reproductive system. Its accuracy was crucial in establishing a prognosis of residual erectile capacity.

The level of the lesion was determined by

Table I Clinical interview

Have you noticed the following signs?

Erections following reflexogenic stimulation

During masturbation

During mutual fondling

During penetration

Erections following psychogenic stimulation

By visual means

By auditory means

In the presence of a partner

Spontaneous erections or appearing outside the context of intercourse

During catheterization

During a clinical examination

During the night

Upon awakening

Natural emissions

Upon genital stimulation

During penetration

With psychogenic erection an initial exploration of perineal reflexes and was followed by exploration of dermatomes. The extent of the lesions was determined by the presence or abscence of voluntary control of perineal muscles as well as dermal sensation below the lesion site.

\section{Exploration of perineal reflexes}

Four perineal reflexes, which are summarized in Table II, were investigated: the bulbocavernosus reflex, the bulbo-anal reflex, the external anal reflex and the cutaneous-anal reflex. While these, as other reflexes, are seldom mediated by only one spinal segment, ${ }^{30,31}$ they are all restricted to the sacral portion of the spinal cord. The presence of these reflexes was therefore used as an indication of sacral activity. Originally, the cremasteric and abdominal reflexes, which are mediated by the thoracic-lumbar segments, were also investigated but the high rate of false negatives made their validity questionable.

The classification of subjects was based on

Table II Exploration of motor pathways and reflexes

\section{Bulbocavernosus reflex (S2-3)}

Pressure stimulation of the glans penis and resulting contraction of the bulbocavernosus muscle

Bulbo-anal reflex (S3-4)

Pressure stimulation of the glans penis and resulting contraction of the anal sphincter

External anal reflex (S3-4)

Stimulation of the anal sphincter through rectal touch and resulting contraction of the anal sphincter

Cutaneous anal reflex (S4-5)

Algic stimulation (with a needle) of the anus and resulting contraction of the sphincter

Voluntary control of external anal sphincter Patient asked to contract his perineal muscles and resulting contraction of the sphincter noted

Voluntary contraction of the bulbocavernosus muscle

Patient asked to contract his perineal muscles and resulting contraction of the bulbocavernosus muscle noted 
the following criteria: when all the perineal reflexes were positive, the lesion was assumed to be above the sacral pathway of erection. Exploration of dermal sensation (see below) further indicated whether it was above the two pathways of erection, or whether it was between the sacral and the TL pathway. When all reflexes were negative, the lesion was said to interrupt the sacral pathway. Further investigation with the dermatomes established whether the damage was restricted to the conus terminalis or whether it extended to the cauda equina.

When the reflexes were mainly, but not completely, negative the lesion was assumed to be localized within the sacral area and was considered partial. When the reflexes were mainly, but not completely, positive the lesion was assumed to be above the sacral pathway and was characterized by erratic responses, as is often the case with spinal cord injured subjects.

\section{Exploration of dermatomes}

Exploration of the dermatomes is illustrated in Figure 2. It was limited to T10 and below since any lesion above T10 was classified as above the two pathways of erection. Investigation of dermal sensation included two modalities: tactile and algic. Originally, thermal sensation was tested as well, but it led to confusing responses from the subjects, who often perceived algic (if the test tube was too hot or too cold) or tactile sensations (if the test tube was lukewarm) instead of thermal ones.

\section{Physiological recordings}

When the initial interview and neurological examination were completed, the subjects

\section{Clinical evaluation of afferent pathways}

TACTILE SENSATION

(POSTERIOR COLUMN SYSTEM)

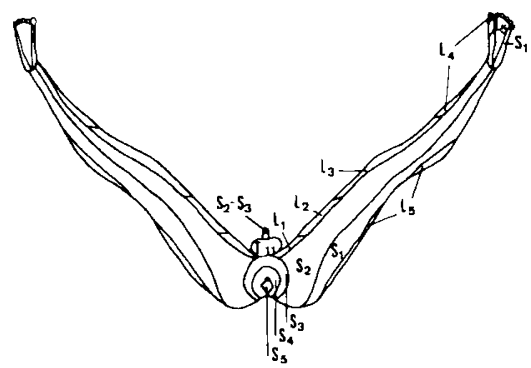

PAIN SENSATION (SPINOTHALAMIC TRACT)

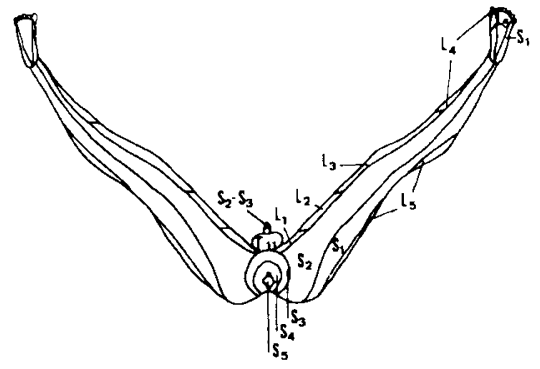

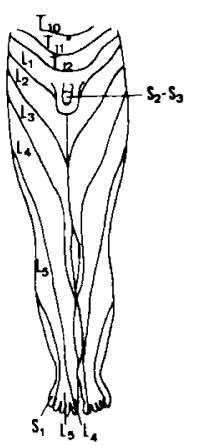

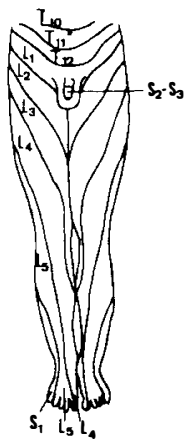

Figure 2 Dermal sensation in the perineum and lower limbs. 
were invited to participate in the physiological recording sessions. The sessions included testing with genital stimulation, in the form of self-masturbation, and testing with psychogenic stimulation, provided by an erotic movie. Originally, the subjects were scheduled for two independent sessions, each of which randomized the order of presentation of the stimulation sources. However, subjects could not always be met twice at the hospital, in which case they were tested in a single session. Genital stimulation was then used first since the carry-over effect from masturbation was believed to be reduced by the lack of genital sensation in spinal cord injured men. In contrast, presenting the movie first was believed to increase the probability of carryover effects from mental images on subsequent masturbation in many subjects.

The subjects' responses were recorded with a penile strain gauge connected to a polygraph. The gauge consisted of a ring of fine silastic tubing filled with mercury and placed at the base of the penis. As erection occurred, distension of the gauge changed the mercury resistance which produced a deflection on the polygraph. Any subject showing an average increase in penile circumference of at least $3 \mathrm{~mm}$, or a maximum increase in penile circumference of at least $6 \mathrm{~mm}$, was scored as responding to the stimulation source. (The detailed analysis of quantitative findings such as average and maximal increases in penile circumference as well as duration of ongoing erections are reported in a separate paper. The general conclusion of this second paper remains along the same lines as that reported below.)

\section{Results}

The results on sexual function are illustrated in Table III. As expected, $100 \%$ of the subjects with lesions above the sacral pathway (AC, AP and BTW) maintained erectile responses to reflexogenic stimulation. Additional responses were observed in those with partial lesions, using the alternate stimulation mode, and occurred in a larger percentage as the lesions reached relatively lower spinal segments.

Subjects with lesions to the sacral pathway (CT and $\mathrm{CE}$ ) were expected to maintain an erectile capacity using primarily psychogenic stimulation. The hypothesis was confirmed in $90 \%$ of the subjects with lesions to the conus terminalis (CT) and almost $80 \%$ of those with cauda equina lesions (CE). Surprisingly, these latter subjects showed similar responses with reflexogenic stimulation. Retrospectively, the finding may indicate that these lesions are inevitably partial, given that the cauda equina is a bundle of fibres which circulates freely in the vertebral column, and may therefore seldom be completely annihilated following a traumatic injury.

The overall results therefore indicate that, when the appropriate mode of stimulation is used, the vast majority of spinal cord injured men maintain erectile capacity. Figure 3 shows that from almost $80 \%$ to $100 \%$ of all paraplegic and tetraplegic men maintain an erectile potential using either reflexogenic or psychogenic stimulation as an optimal stimulation source.

While the above findings were obtained from physiological recordings, they were

Table III Erectile capacity as a function of lesion type

\begin{tabular}{|c|c|c|c|c|c|c|}
\hline \multirow[b]{2}{*}{$\begin{array}{l}\text { Pathways of } \\
\text { erection }\end{array}$} & \multicolumn{3}{|c|}{ Reflexogenic erection } & \multicolumn{3}{|c|}{ Psychogenic erection } \\
\hline & $\begin{array}{l}\text { Total number } \\
\text { of subjects }\end{array}$ & $\begin{array}{l}\text { Frequency } \\
\text { of responses }\end{array}$ & $\%$ & $\begin{array}{l}\text { Total number } \\
\text { of subjects }\end{array}$ & $\begin{array}{c}\text { Frequency } \\
\text { of responses }\end{array}$ & $\%$ \\
\hline $\mathrm{AC}$ & 15 & 15 & 100 & 12 & 3 & 25 \\
\hline AP & 15 & 15 & 100 & 14 & 8 & 57 \\
\hline BTW & 13 & 13 & 100 & 12 & 8 & 67 \\
\hline CT & 8 & 6 & 75 & 10 & 9 & 90 \\
\hline $\mathrm{CE}$ & 15 & 12 & 80 & 18 & 14 & 78 \\
\hline
\end{tabular}


Optimal mode

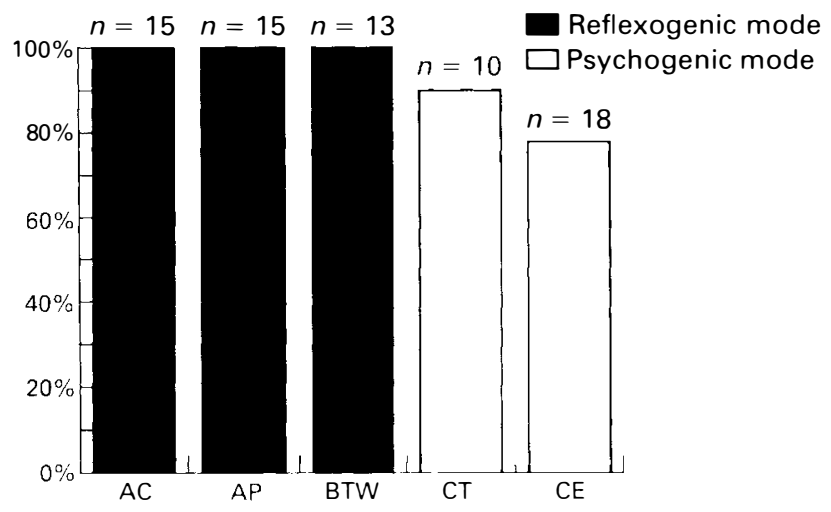

Figure 3 Erectile responses to the optimal source of stimulation, defined as reflexogenic for the group of complete (AC) and partial (AP) lesions above the two pathways of erection and the group between the two pathways (BTW) and defined as psychogenic for the group of lesions to the conus terminalis $(\mathrm{CT})$ and cauda equina $(\mathrm{CE})$.

compared to those predicted from our original prognoses and those predicted from the patients' subjective reports. The results generally indicate that sexual function can be accurately predicted by prognoses when the optimal stimulation mode is considered. Subjective reports are only consistent with their physiological recordings when the lesion is above the sacral pathway, that is, when erection is maintained in response to direct stimulation of the penis.

Figures 4-8 summarize the comparative findings, which were tested using Fisher's exact probability test. Nonsignificant results indicated that predictions based on our prognoses or on the subjects' reports agreed with physiological recordings. Significant results indicated that predictions underestimated the individual's real erectile capacity.

Figure 4 shows the results for subjects with complete lesions above the two pathways of erection (AC). The prediction made from our prognosis, using the optimal stimulation, was perfectly consistent with physiological recordings $(p=1.00)$. Subjective reports also agreed with the physiological recordings, but with a slightly less accurate prediction $(p=0.24)$. The predictions made for the alternate mode of stimulation (i.e. psychogenic) were not as perfect, but the difference between predictions and physiological recordings was not significant for either prognosis $(p=0.11)$ or subjective report $(p=0.11)$.

Figures 5 and 6 again show perfect predictions from prognosis ( $p=1.00$ for both AP and BTW), using optimal stimulation, and slightly less accurate predictions from subjective reports $(p=0.24$ for $\mathrm{AP}$ and $p=0.11$ for BTW). Prognoses for the alternate stimulation surprisingly overestimated the individual's actual capacity, but not to a significant extent $(p=0.13$ for AP and $p=0.05$ for BTW). Subjective reports, which tend to underestimate erectile capacity, were more accurate in predicting physiological recordings $(p=0.30$ for $\mathrm{AP}$ and $p=0.33$ for BTW).

In contrast to the above, lower lesions (CT and CE) were associated with much more erratic responses, especially from subjective reports and on the alternate form of simulation. Figure 7 shows that prediction based on prognosis, using the optimal stimulation, was very high $(p=0.50)$ for CT subjects while that of subjective reports was very low $(p=0.06)$. Both prognoses and subjective reports significantly underestimated erectile capacity with alternate stimulation, the patients' reports underestimating capacity ( $p=0.007)$ to an even further extent than prognoses $(p=0.02)$.

Individuals with cauda equina (CE) 
AC

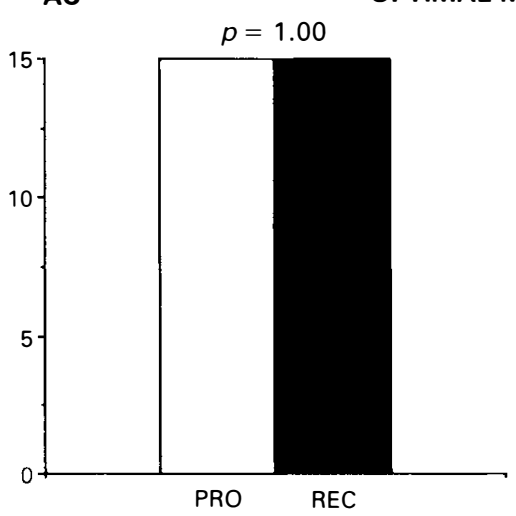

OPTIMAL MODE: REFLEXOGENIC

$(n=15)$

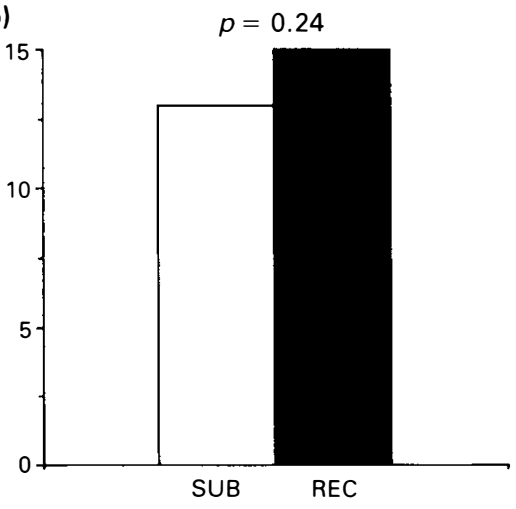

\section{ALTERNATE MODE: PSYCHOGENIC}
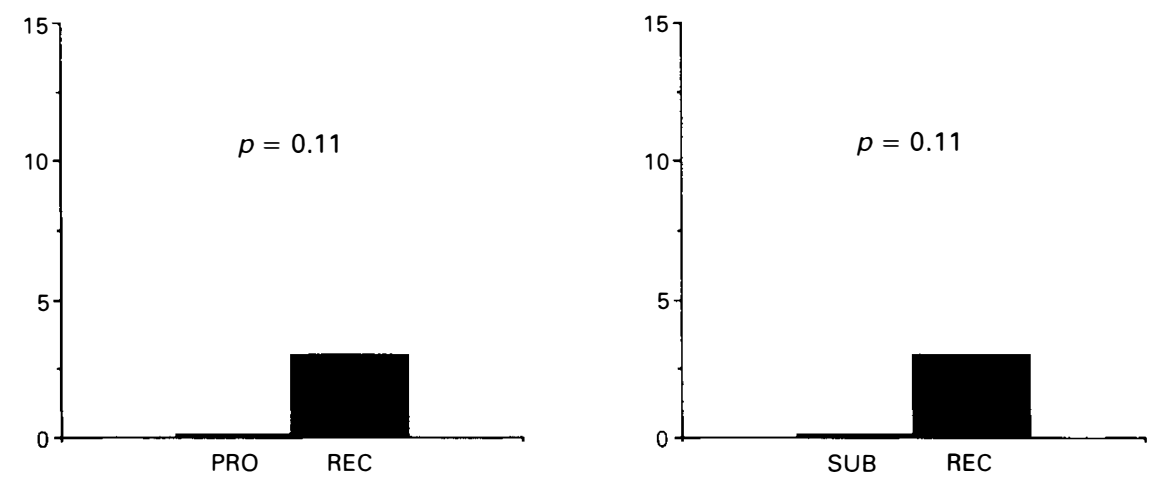

Figure 4 Comparison between prognosis (PRO) and physiological recordings (REC) as well as subjective reports (SUB) and physiological recordings using the optimal and the alternate source of stimulation for the group of complete lesions above the two pathways of erection (AC).

lesions significantly underestimated their capacity using both optimal $(p=0.04)$ and alternate stimulation $(p=0.001)$. Prognosis predicted capacity with optimal stimulation $(p=0.05)$, but underestimated erectile function with the alternate form of stimulation $(p=0.004)$.

Aside from the above data on erectile function, data on sperm emission were collected during the experiment. As for the initial interview, emission was defined as the appearance of a whitish, viscous substance which could be expelled or dribble along the urethra. Table IV shows that up to $70 \%$ of the subjects with conus terminalis lesions exhibited sperm emission during physiological testing with psychogenic stimulation.
An additional $30 \%$ reported maintenance of emission during the initial interview, for a total of $100 \%$ of subjects with CT lesions maintaining a reproductive potential. Of the other subjects, up to $47 \%$ of those with other lesions maintained naturally occurring emissions and these natural emissions generally appeared following psychogenic stimulation.

\section{Discussion}

The results from this study show that sexual function is maintained in the vast majority of spinal cord injured men. Considering the optimal mode of stimulation for each group, $100 \%$ of the subjects with lesions above the 

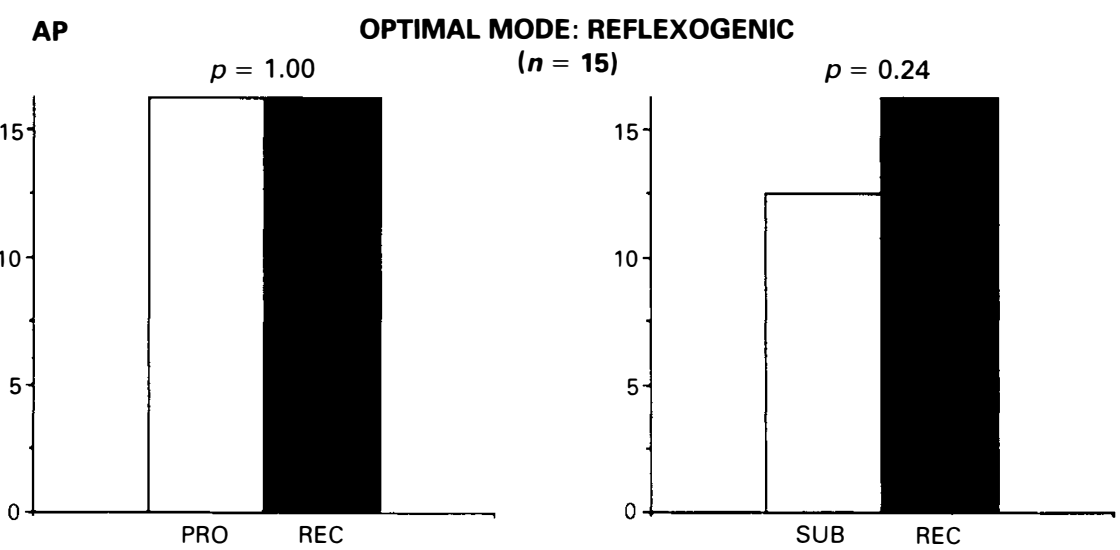

ALTERNATE MODE: PSYCHOGENIC
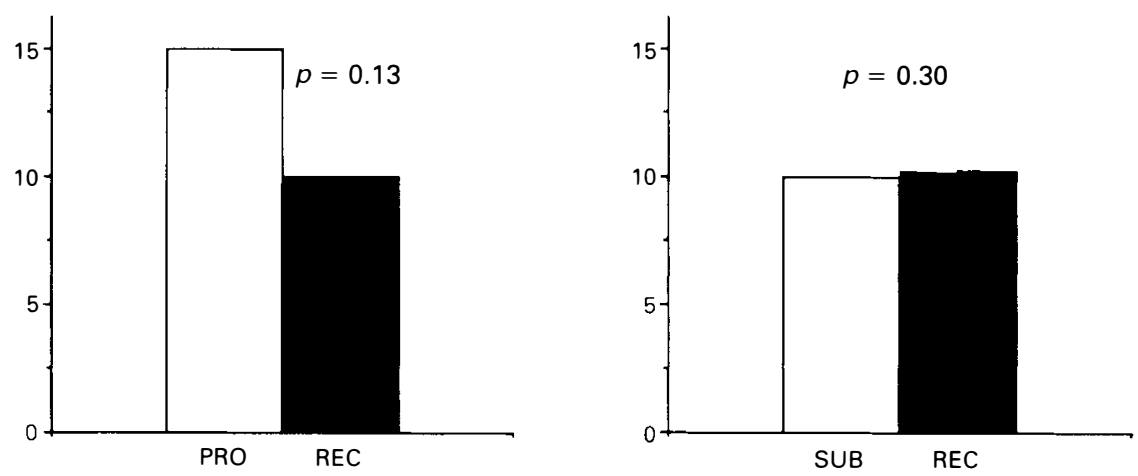

Figure 5 Comparison between prognosis (PRO) and physiological recordings (REC) as well as subjective reports (SUB) and physiological recordings using the optimal and the alternate source of stimulation for the group of partial lesions above the two pathways of erection (AP).

sacral pathway, and up to $90 \%$ of the subjects with damage to the sacral pathway, maintain erectile capacity. The data on emission further indicate that $100 \%$ of the subjects with lesions to the conus terminalis maintain seminal emission in response to psychogenic stimulation and that up to $47 \%$ of the subjects with other lesions are capable of naturally occurring emissions.

These data are far more optimistic than other reports on sexual function in spinal cord injured men..$^{20,22,23}$ We believe that this stems from two essential factors: the classification system and the use of physiological recordings. The classification system, which we used and which has been used by others with success, ${ }^{21,32}$ defines the groups in terms of their lesion level with respect to the innervation of the male reproductive system. Such a system gives a criterion to define the primary mode of stimulation which will induce erection, which increases group homogeneity and the success rate associated with optimal stimulation. Partial lesions may similarly benefit from optimal stimulation but will also gain additional response using an alternate mode of stimulation. Sexual potential is therefore a definite reality for paraplegic and tetraplegic men.

The high success rate of our results may also stem from the use of physiological recordings. Earlier studies have used subjective reports as the best methodology 


\section{BTW}

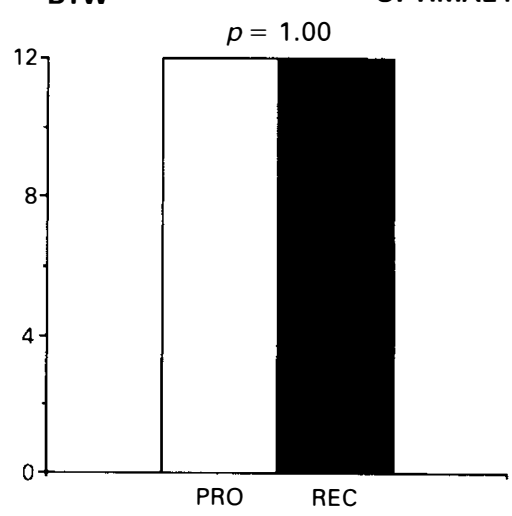

OPTIMAL MODE: REFLEXOGENIC

$$
(n=13)
$$

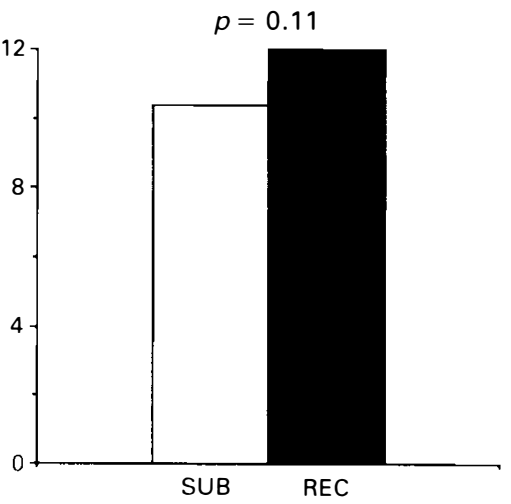

\section{ALTERNATE MODE: PSYCHOGENIC}
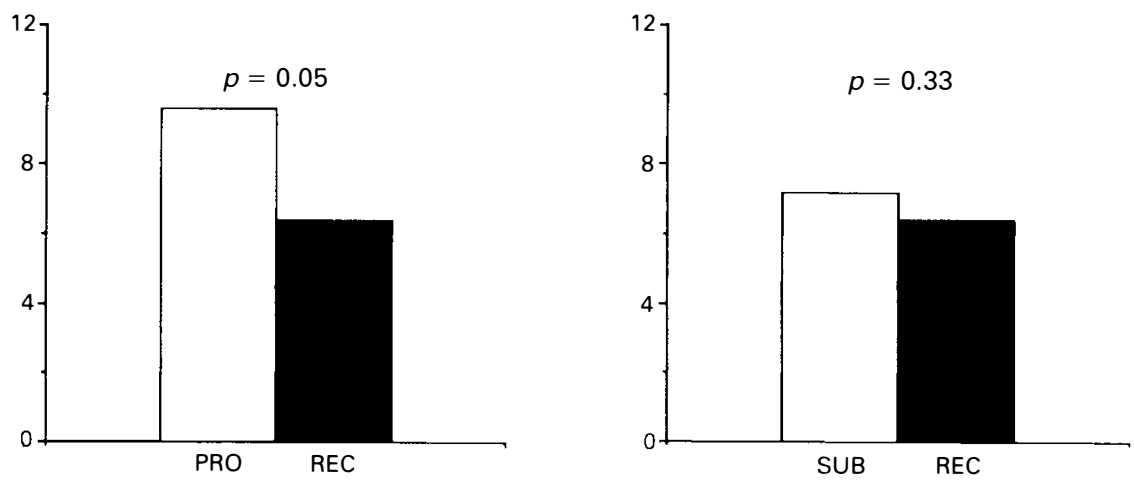

Figure 6 Comparison between prognosis (PRO) and physiological recordings (REC) as well as subjective reports (SUB) and physiological recordings using the optimal and the alternate source of stimulation for the group of lesions between the two pathways of erection (BTW).

available at the time $e^{20,22,23}$ but our data as well as that of others ${ }^{24}$ show that spinal cord injured men often underestimate their residual capacity with psychogenic stimulation. Indeed, this study attempted to verify whether physiological recordings exceeded the subjects' own awareness of sexual capacity, and whether prognoses based on a thorough neurological examination could increase the prediction of sexual function on the part of the clinician. The results support the view that subjects underestimate their sexual potential and that prognoses increase prediction, at least for the optimal mode of stimulation. Clinical consultation with spinal cord injured men should therefore use, as much as possible, physiological recordings to avoid distortion of the patient's actual erectile capacity.

The data on emission also reveal very optimistic results, especially for the group with a lesion to the conus terminalis (CT). The high success rate of $100 \%$ may again reflect the classification system since the lesions were restricted to the tip of the spinal cord. The thoracic-lumbar pathway was therefore left intact and allowed transmission of psychogenic erection as well as emission. However, systematic spermograms were not performed on the subjects since the finding was originally unexpected. Spermograms achieved on a few subsequent CT subjects revealed the presence of spermatozoids and a potentially fertile 

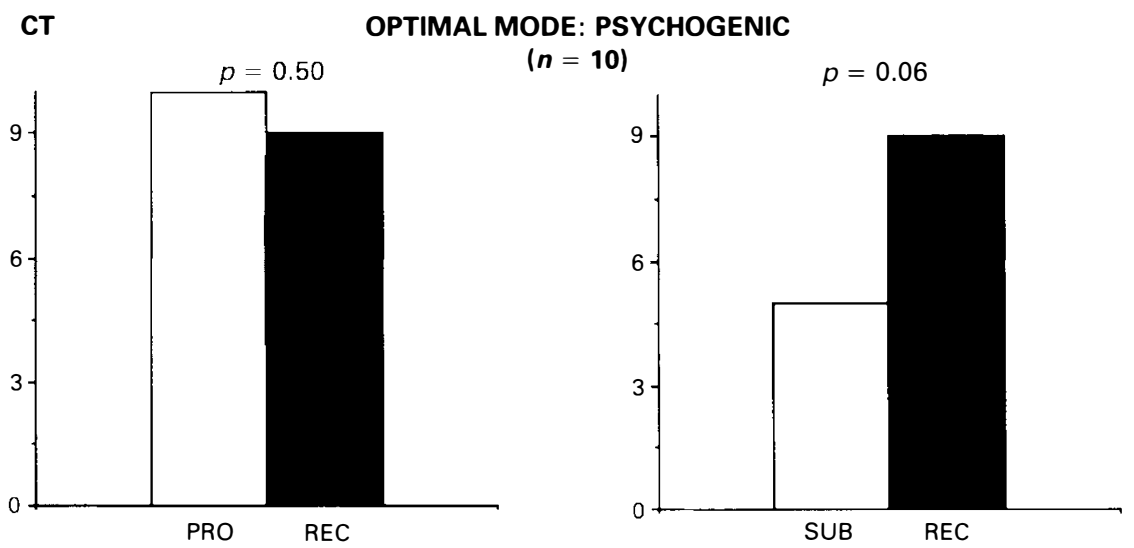

ALTERNATE MODE: REFLEXOGENIC
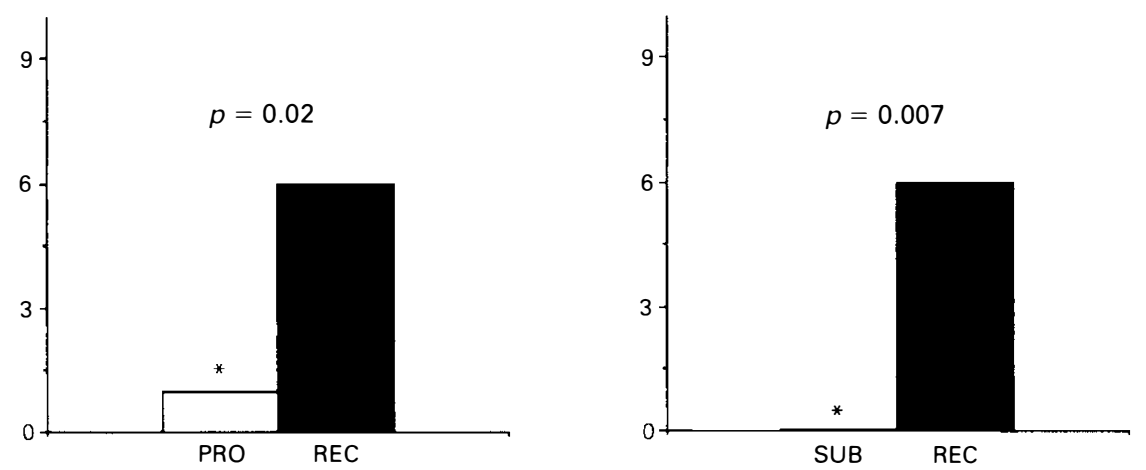

Figure 7 Comparison between prognosis (PRO) and physiological recordings (REC) as well as subjective reports (SUB) and physiological recordings using the optimal and the alternate source of stimulation for the group of lesions to the conus terminalis (CT).

sperm count (eg 30 million spermatozoids in one subject) but it remains unknown whether these emissions are always accompanied by spermatozoids.

These overall findings are therefore consistent with the innervation of the male reproductive system. While higher lesions spare the sacral pathway, erectile capacity is maintained through a reflex arc using genital stimulation. Lower lesions spare the TL pathway and maintain erectile capacity using psychogenic stimulation as well as emission, which is elicited through the contraction of the internal reproductive organs (vas deferens, seminal emission, prostate). The findings are also consistent with our previous study on rats which demonstrated erectile capacity in a controlled animal model of paraplegia. ${ }^{34}$ Furthermore, the present results are consistent with our clinical experience which reveals that subjects with lower lesions to the conus terminalis (CT) often complain of erectile dysfunctions that are secondary to premature ejaculation, that is, erection does not hold because emission follows immediately after initial tumescence. A descriptive report from Szasz ${ }^{32}$ similarly suggests organically-based premature ejaculation in a paraplegic man who solved his problem by the same procedure than we have suggested: using a ring which will retard ejaculation and thereby sustain erection. The use of rings should nevertheless be suggested with 

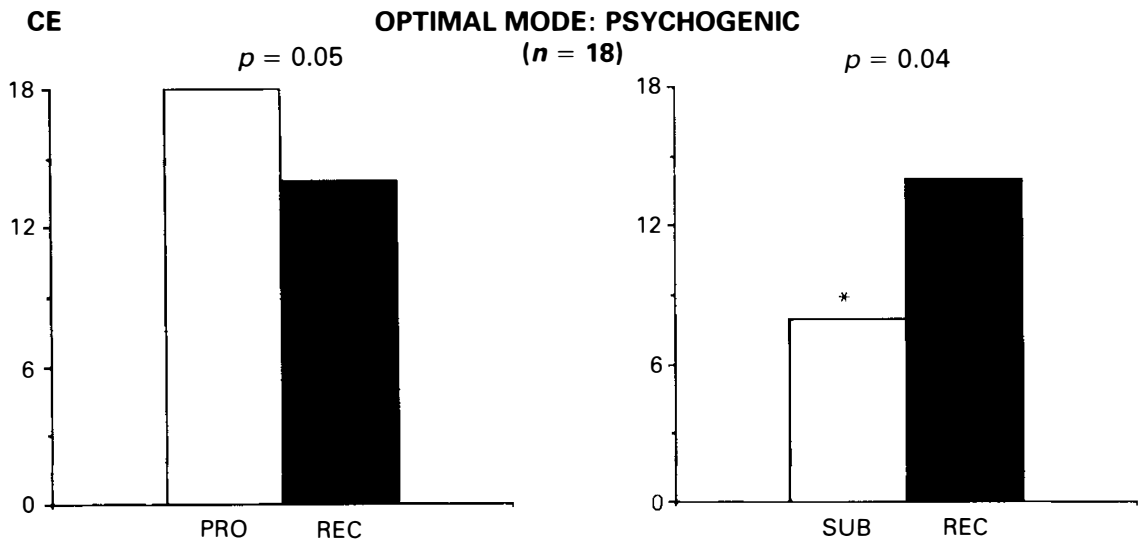

ALTERNATE MODE: REFLEXOGENIC
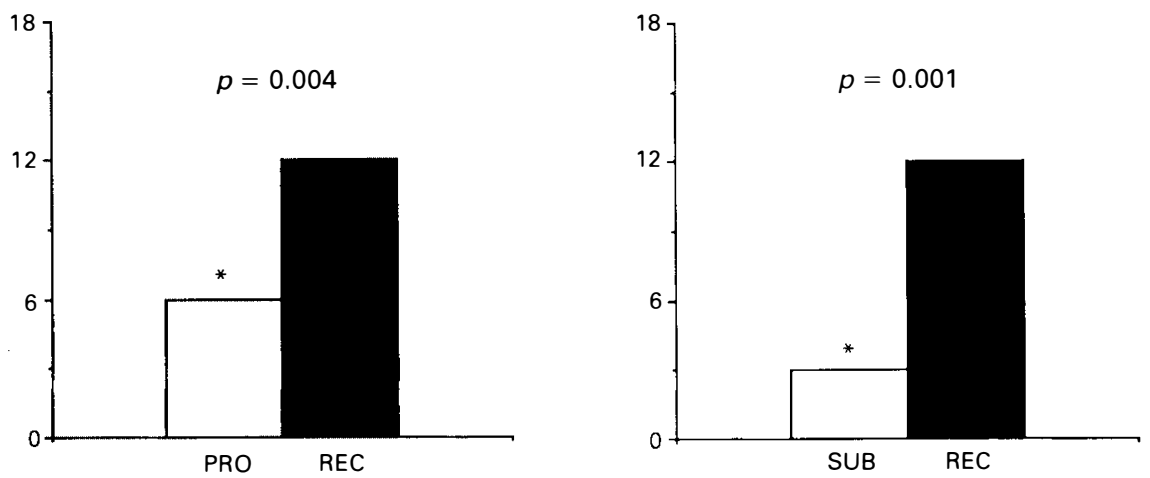

Figure 8 Comparison between prognosis (PRO) and physiological recordings (REC) as well as subjective reports (SUB) and physiological recordings using the optimal and the alternate source of stimulation for the group of lesions to the cauda equina (CE).

Table IV Potential for seminal emission as a function of lesion type

\begin{tabular}{|c|c|c|c|c|c|c|c|}
\hline \multirow[b]{2}{*}{$\begin{array}{l}\text { Pathways } \\
\text { of } \\
\text { erection }\end{array}$} & \multirow{2}{*}{$\begin{array}{c}\text { Total } \\
\text { number } \\
\text { of } \\
\text { subjects }\end{array}$} & \multicolumn{2}{|c|}{ Recorded emissions } & \multicolumn{2}{|c|}{ Reported emissions } & \multicolumn{2}{|c|}{ Total emissions } \\
\hline & & $\begin{array}{l}\text { Number of } \\
\text { observed } \\
\text { responses }\end{array}$ & $\%$ & $\begin{array}{l}\text { Number of } \\
\text { additional } \\
\text { responses }\end{array}$ & $\%$ & $\begin{array}{l}\text { Number of } \\
\text { responses }\end{array}$ & $\%$ \\
\hline $\mathrm{AC}$ & 15 & 2 & 13 & 2 & 13 & 4 & 27 \\
\hline AP & 15 & 1 & 7 & 6 & 40 & 7 & 47 \\
\hline BTW & 13 & 3 & 23 & 3 & 23 & 6 & 46 \\
\hline $\mathrm{CT}$ & 10 & 7 & 70 & 3 & 30 & 10 & 100 \\
\hline CE & 15 & 1 & 7 & 5 & 33 & 6 & 40 \\
\hline
\end{tabular}

caution given the rare but traumatic condition of penile incarceration. ${ }^{35}$ Intracavernous injections can also be used to delay emission, but it is our experience that it sometimes delays emission to the point where it no longer appears. Paraplegic men should therefore be advised about the possible adversive effect of intracavernous injections on reproductive function.

The overall results of this study should 
not be taken to suggest that patients should forego other forms of treatment to compensate for their perceived sexual difficulty. While our findings are very optimistic, they are based on research criteria which define erection as an average increase in penile circumference of at least $3 \mathrm{~mm}$. It may be that this criteria, although clearly physiological, is not sufficient for intercourse. It may also be that tumescence, which is sustained in the vast majority of subjects, is not always accompanied with sufficient rigidity to allow penetration. However, one cannot exclude the possibility that the above results reflect the true sexual potential of spinal cord injured men and that these men depreciate their erectile capacity when they are subjectively asked to describe their erection. Spinal cord injured men can certainly depreciate their erectile capacity if they compare it to preinjury level, and their response may be affected by other factors than the lesions such as depression, financial worries, loss of significant others and the like. While these psychological variables may affect sexual function independently from the lesion, our optimistic findings suggest that the contribution of psychological variables on an organic etiology should be explored more often in this population of patients. Spinal cord injured men should therefore be assessed, to the same extent as palliative treatments are offered, so that the individual is left with documented information about his remaining function which may give him a sense of control over this intimate part of his life.

\section{Acknowledgements}

The authors wish to thank Dr Clothilde CzybaGauthier for her medical assistance and Ms Danielle Choquette, Mr Pierre Gougeon and Ms Johanne Gravel for their participation in the research program. This research was funded by FRSQ (Québec, Canada). Over the entire project, the principal investigator received a postdoctoral fellowship from FCAR (Québec, Canada) and a University Research Fellowship from FRSQ.

\section{References}

1 Bodner DR, Lindan R, Leffler E, Kursh ED, Resnick MI (1987) The application of intracavernous injection of vasoactive medication for erection in men with spinal cord injury. $J$ Urol 138: 310-311.

2 Bodner DR, Leffler B, Frost F (1992) The role of intracavernous injection of vasoactive medication for the restoration of erection in spinal cord injured males: a three year follow up. Paraplegia 30: 118-120.

3 Lloyd LK, Richards JS (1989) Intracavernous pharmacology for management of erectile dysfunction in spinal cord injury. Paraplegia 27: 457-464.

4 Lee LM, Stevenson WD, Szasz G (1989) Prostaglandin E1 versus phentolamine/papaverine for the treatment of erectile impotence: a double-blind comparison. J Urol 141: 549-550.

5 Sidi AA, Cameron JS, Dykstra DD, Reinberg Y, Lange PH (1987) Vasoactive intracavernous pharmacotherapy for the treatment of erectile impotence in men with spinal cord injury. J Urol 138: 539-542.

6 Wyndaele JJ, de Meyer JM, de Sy WA, Claessens H (1986) Intracavernous injection of vasoactive drugs, an alternative for treating impotence in spinal cord injury patients. Paraplegia 24: 271-275.

7 Golji H (1979) Experience with penile prosthesis in spinal cord injury patients. J Urol 121: 288-289.

8 Iwatsubo E, Tanaka M, Takahashi K, Akatsu T (1986) Non-inflatable penile prosthesis for the management of urinary incontinence and sexual disability of patients with spinal cord injury. Paraplegia 24: 307-310.

9 Light JK, Scott FB (1981) Management of neurogenic impotence with inflatable penile prosthesis. Urology XVII(4): $341-343$.

10 Perkash I, Kabalin JN, Lennon S, Wolfe V (1992) Use of penile prosthesis to maintain external condom catheter drainage in spinal cord injury patients. Paraplegia 30: 327-332.

11 Van Arsdalen KN, Klein FA, Hackler RH, Brady SM (1981) Penile implants in spinal cord injury patients for maintaining external appliances. J Urol 126: 331-332.

12 Heller L, Keren O, Aloni R, Davidoff G (1992) An open trial of vacuum penile tumescence: constriction therapy for neurological impotence. Paraplegia 30: 550-553.

13 Nadig PW, Ware FC, Blumoff R (1986) Noninvasive device to produce and maintain an erection-like state. Urology XXVII(2): 126-131.

14 Z'asler ND, Katz PG (1989) Synergist erection system in the management of impotence secondary to spinal cord injury. Arch Phys Med Rehabil 70: 712-716.

15 Claes H, Baert L (1989) Transcutaneous nitroglycerin therapy in the treatment of impotence. Urol Int 44: $309-312$.

16 Owen AA, Saunders F, Harris C, Fenemore J, Reid K, Surridge D et al (1989) Topical nitroglycerin: A potential treatment for impotence. J Urol 141: 546-548. 
17 Sonksen J, Biering-Sorensen F (1992) Transcutaneous nitroglycerin in the treatment of erectile dysfunction. Paraplegia 30: 554-557.

18 Collins KP, Hackler RH (1988) Complications of penile prostheses in the spinal cord injury population. $J$ Urol 140: 984-985.

19 Rossier AB, Fam BA (1984) Indication and results of semirigid penile prostheses in spinal cord injury patients: Long term followup. J Urol 131: 59-62.

20 Bors E, Comarr E (1960) Neurological disturbances of sexual function with special reference to 529 patients with spinal cord injury. Urol Surv 10: 191-222.

21 Chapelle PA, Durand J, Lacert P (1980) Penile erection following complete spinal cord injury in man. $B r J$ Urol 52: 216-219.

22 Comarr AE (1970) Sexual function among patients with spinal cord injury. Urol Int 25: 134-168.

23 Slot O, Drewes A, Andreasen A, Olsson A (1989) Erectile and ejaculatory function of males with spinal cord injury. Int Disabil Studies 11: 75-77.

24 Kennedy S, Over R (1990) Psychophysiological assessment of male sexual arousal following spinal cord injury. Arch Sex Behav 19(1): 15-27.

25 Lamid S (1985) Nocturnal penile tumescence studies in spinal cord injured males. Paraplegia 23: 26-31.

26 Fitzpatrick WF (1974) Sexual function in the paraplegic patient. Arch Phys Med Rehabil 55: 221-227.

27 Tsuji I, Nakajima F, Morimoto J, Nounaka Y (1961) The sexual function in patients with spinal cord injury. Urol Int 12: 270-280.

28 Zeitlin AB, Cotrell, TL, Lloyd FA (1957) Sexology of the paraplegic male. Fertil Steril 4: 337-344.

29 Szasz G (1986) Sexual function in the spinal cord injured. In: Bloch RF, Basbaum M, editors. Management of Spinal Cord Injuries. Williams \& Wilkins, Baltimore.

30 Ertekin C, Reel F (1976) Bulbocavernosus reflex in normal men and in patients with neurogenic bladder and/or impotence. J Neurol Sci 28: 1-15.

31 Mersdorf A, Schmidt RA, Tanagho EA (1933) Topographic-anatomical basis of sacral neurostimulation: Neuroanatomical variations. J Urol 149: 345-349.

32 Szasz G (1991) Sex and disability are not mutually exclusive. Evaluation and management. West J Med 154: $560-563$.

33 Wahle H, Jochheim KA (1974) Studies on neurogenic disorders of sexual function in 56 paraplegic men with complete irreversible injuries of the spinal cord or the cauda equina. Arch Sex Behav 3: 184-188.

34 Courtois FJ, MacDougall JC, Sachs BD (1993) Erectile mechanism in paraplegia. Physiol Behav 53: 721-726.

35 Vahasarja VJ, Hellstrom PA, Serlo W, Kontturi MJ (1993) Treatment of penile incarceration by the string method: 2 case reports. J Urol 149: 372-373. 